\title{
Autonomous Power Supply System for Light Sensor of Illumination Measurement Test Bench
}

\author{
Olegs Tetervenoks (Doctoral Student, Riga Technical University), \\ Ilya Galkin (Professor, Riga Technical University), \\ Jelena Armas (Researcher, Tallinn University of Technology)
}

\begin{abstract}
Usually wireless devices require autonomous power supply. They are equipped with radio frequency transceiver modules with relatively high energy consumption especially in data transmission mode. This also means that autonomous power supply of wireless device requires relatively large energy storage. Rechargeable battery in this case is a good solution, but the charging process of a battery takes a long time. In this paper the use of supercapacitor as energy storage for autonomous power supply of wireless node is further elaborated on the example of light sensor for illumination measurement test bench.
\end{abstract}

Keywords - Lighting, optical variables measurement, wireless sensor networks, energy storage, supercapacitors.

\section{INTRODUCTION}

The system for the estimation of artificial light sources was discussed in detail in [1] and the prototype of photodetector has been designed. The purpose of this illumination measurement system is to estimate light distribution of artificial light source in particular direction. The system consists of a matrix of illumination measurement elements (sensors) as shown in Fig. 1. It was decided to implement wireless communication for sensors. The use of wireless interface is more flexible. It gives the possibility to use sensors also for on-street measurements (Fig. 1).

In this case sensors are wireless devices requiring autonomous power supply. Energy storage capacity should be sufficient enough for working offline for a reasonable time.

The choice of energy storage for wireless node depends directly on the task, and hence on the mode of its operation. Rechargeable batteries as an autonomous power supply are widely discussed in literature [2] - [4], so this article skips a closer look on them. The main focus of this article is on the consideration of a supercapacitor as energy storage.

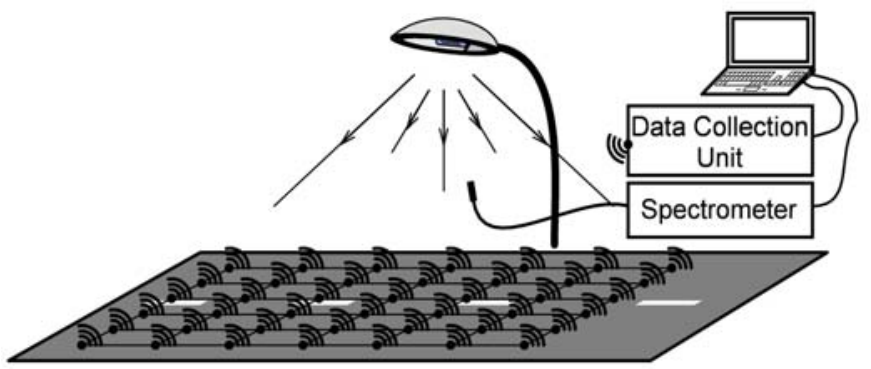

Fig. 1. Setup for experimental measurements
Supercapacitor as an energy source for wireless sensor nodes in general case was discussed in [5]. This article is focused on the specific application of supercapacitor in wireless node of illumination measurement test bench with its own specific requirements.

Batteries are a convenient solution for wireless devices. They allow achieving great duration of operation. At the same time batteries have disadvantages such as long charging time and limited lifetime. Energy accumulation time is becoming more critical parameter with increasing number of wireless devices of the system.

Supercapacitors do not have these shortcomings. However, the stored energy is low if to compare with a battery. To achieve the required operation time it is necessary to optimize energy consumption of individual nodes of wireless device.

This article examines in more detail autonomous power supply of such a sensor, taking into account economical aspects for the total number of wireless sensors. The next section briefly describes requirements for determination of necessary number of measurement points (number of sensors).

\section{DETERMINATION OF THE REQUIRED NUMBER OF SENSORS}

The configurations (number of sensors and distance between them) of measurement sensor grids are closely related to the configuration and function of the lighting equipment. It is possible to emphasize two occasions where such equipment is used in different ways: indoor and outdoor lighting.

The indoor lighting must provide adequate work and life environment for human beings. These requirements are specified in the European standard EN-12464-1:2011: "Light and lighting. Lighting of work places. Indoor work places."

Accordingly to EN-12464-1:2011 the illumination measurements require definition of a matrix with measurement points for the task area. The maximum size of grid cells is defined by the equation:

$$
p=0.2 \times 5^{\log _{10}(d)} .
$$

where:

$d-$ is the longest dimension of the task area $(\mathrm{m})$;

$p$ - is the maximum grid cell size (m), which has to be $p \leq 10 \mathrm{~m}$;

For the described measurement test bench the task area is $\mathrm{a}=2 \mathrm{~m}$ and $\mathrm{b}=2 \mathrm{~m}$, that gives the longest size $\mathrm{d}=2 \mathrm{~m}$ and satisfactory ratio of length to width $=1$. Then the expression (1) gives maximal size of $0.3 \mathrm{~m}$, but minimal linear number of 
measurement points is 6 . Then the total number of measurement points on the task is $6 \times 6=36$.

Road measurements are described in another standard EN13201-3:2007: "Calculation of performance". The standard defines the statistical evaluation field that consists of uniformly distributed measuring points "regions", in the raster $6 \times 10$ (road width $x$ length of the evaluation field). The same approach and grid could be applied to the field measurements of illuminance on roads. Therefore the number of sensors for such measurements is 60 .

The final number of sensors required for the proposed test bench is 36 because it provides instantaneous indoor measurements on the required task area and sequential field measurements over $6 \times 10$ raster.

As mentioned previously the time of energy accumulation for energy storage of the wireless nodes becomes critical in this situation. The following sections are aimed to reduce the charging time.

\section{Light SENSOR ENERGy CONSUMPTION}

\section{A. Light sensor description}

In our case the sensor consists of ambient light sensor (APDS-9300), radio frequency transceiver (MRF24j40MA), microprocessor (MSP430F2254) and voltage regulator and energy storage. A charger also can be integrated into the device (Fig. 2). Ambient light sensor is the key element, so more detailed consideration of it is given in this article.

\section{B. Assessment of Energy Consumption of Sensor Node}

For wireless devices it is very important to reduce power consumption to a minimum. For this purpose it is necessary to estimate power consumption of different nodes of the device at different operation modes.

Table I shows the values of the current consumption of individual nodes of sensor at typical and worst conditions (data specified in according device datasheet).

TABLE I

ENERGY CONSUMPTION OF DIFFERENT NODES AT DIFFERENT OPERATION MODES

\begin{tabular}{|c|c|c|c|c|}
\hline \multirow{2}{*}{ Node } & \multicolumn{2}{|c|}{ Active mode } & \multicolumn{2}{c|}{$\begin{array}{c}\text { Low power mode or } \\
\text { power down }\end{array}$} \\
\hline & Typ & Max & Typ & Max \\
\hline Ambient light sensor & $0.24 \mathrm{~mA}$ & $0.6 \mathrm{~mA}$ & $3.2 \mu \mathrm{A}$ & $15 \mu \mathrm{A}$ \\
\hline Transceiver & $19 \mathrm{~mA}$ & $23 \mathrm{~mA}$ & $2 \mu \mathrm{A}$ & - \\
\hline Microprocessor & $340 \mu \mathrm{A}$ & $550 \mu \mathrm{A}$ & $41 \mu \mathrm{A}$ & $120 \mu \mathrm{A}$ \\
\hline
\end{tabular}

Table I does not take into account the energy consumption for data transmission between the individual nodes of photodetector. To transfer the data between the microprocessor and ambient light sensor $\mathrm{I}^{2} \mathrm{C}$ interface is used. Data transfer between the transceiver and the microprocessor is carried out by SPI interface.

$\mathrm{I}^{2} \mathrm{C}$ interface has two lines. Both SDA (Serial Data Line) and SCL (Serial Clock) lines are connected to a positive supply voltage via a pull-up resistor (Fig. 3). The lines are connected to open-drain or open-collector output stages of the devices. During data transfer additional power losses appear in pull-up resistors [6].

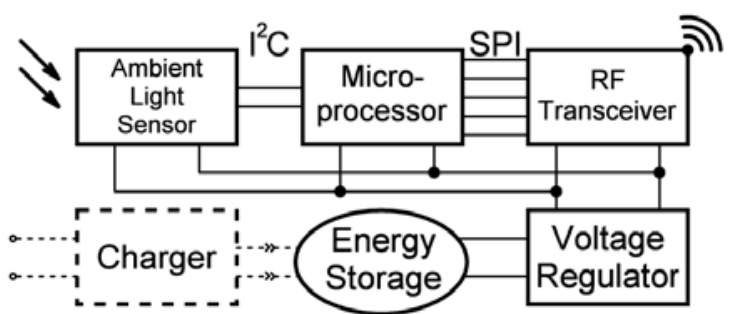

Fig. 2. Block diagram of light sensor

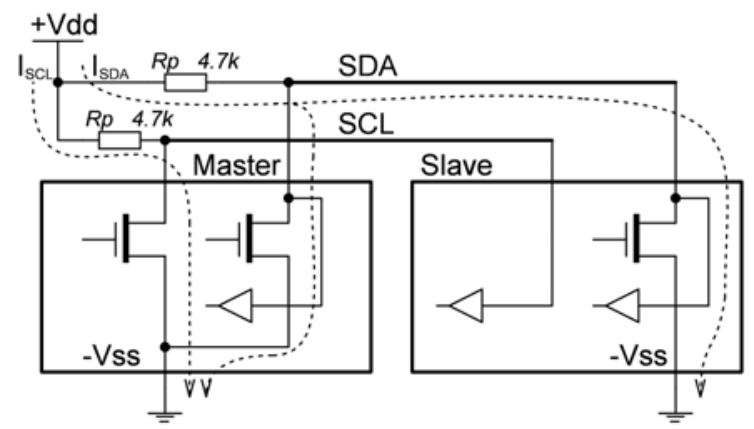

Fig. 3. $\mathrm{I}^{2} \mathrm{C}$ interface and current consumption of SDA and SCL lines.

To simplify calculations we assume that the line current is limited only by the pull-up resistor. The lines have no capacitance and inductance. On-state resistance of the internal circuits of the devices is equal to zero. Off-state resistance is infinite. In this case the average current consumption of SCL line during data transfer can be calculated by the equation:

$$
I_{S C L}=\frac{1}{T \cdot R p} \int_{0}^{T}\left(V_{d d}-V_{S C L}(t)\right) d t=\frac{V_{d d}}{2 R p},
$$

where $\mathrm{V}_{\mathrm{SCL}}$ is SCL line voltage, $\mathrm{Rp}$ is the value of pull-up resistor and $\mathrm{T}$ is the period of clock signal of $\mathrm{I}^{2} \mathrm{C}$-bus (Fig. 4).

The consumed energy of SCL line $\Delta \mathrm{E}_{\mathrm{SCL}}$ in joules can be found from the expression:

$$
\Delta E_{S C L}=\frac{T_{a c t}}{T} \int_{0}^{T} \frac{\left(V_{d d}-V_{S C L}(t)\right)^{2}}{R p} d t=\frac{T_{a c t} \cdot V_{d d}^{2}}{2 R p},
$$

where $\mathrm{T}_{\mathrm{act}}$ is the duration of data transfer in seconds.

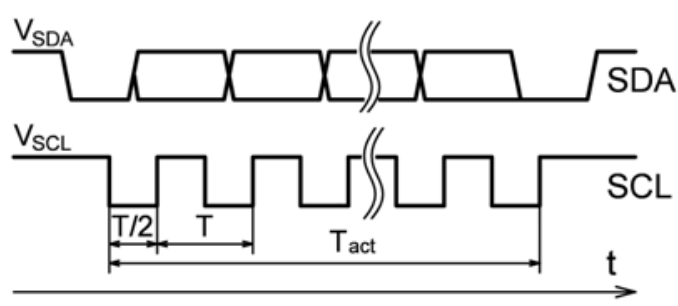

Fig. 4. $\mathrm{I}^{2} \mathrm{C}$-bus SCL and SDA line signals [6].

SDA line current and energy consumption can not be calculated analytically, because these values depend on transferred data. However, in the worst case these values are equal to twice the value of (2) and (3): 


$$
\begin{gathered}
I_{S D A}=V_{d d} / R p, \\
\Delta E_{S D A}=\left(T_{a c t} \cdot V_{d d}^{2}\right) / R_{p},
\end{gathered}
$$

In our case $\mathrm{I}^{2} \mathrm{C}$ interface operates in standard mode (up to $100 \mathrm{kHz}$ ). Pull-up resistor value is $4.7 \mathrm{k} \Omega$. It was experimentally tested, that higher resistance values in our configuration can lead to unstable operation of $\mathrm{I}^{2} \mathrm{C}$.

For the worst case we assume that data transfer between microprocessor and ambient light sensor occurs continuously. According to (2) and (4) current consumption of $\mathrm{I}^{2} \mathrm{C}$-bus is equal to $890 \mu \mathrm{A}$, which is comparable with current consumption of microprocessor at $1 \mathrm{MHz}$ clock frequency.

Total power consumption of sensor without considering the efficiency of voltage regulator is equal to the sum of power consumptions of individual nodes and power consumption on data transmission. For the worst case power consumption is equal to $\mathrm{P}=\mathrm{V} \cdot \mathrm{I}=2.8 \mathrm{~V} \cdot(23+0.6+0.6+0.9) \mathrm{mA}=70 \mathrm{~mW}$.

Depending on its efficiency the voltage regulator can cause a significant change in energy consumption.

\section{Measures to Reduce Energy Consumption}

Sensor nodes supply voltage value $\mathrm{V}_{\mathrm{dd}}$ specified in Table I is selected to be $2.8 \mathrm{~V}$, which is less than typical $3.3 \mathrm{~V}$ but sufficient for stable operation of each node. This approach reduces energy consumption by reducing the current consumption of digital IC at lower supply voltage. Also in the case of using one cell supercapacitor or parallel connection of capacitors difference between input and output voltages of voltage regulator decreases. This improves efficiency of voltage regulator and increases operation time of the device.

Optimization of energy consumption of individual nodes of wireless device is needed to increase operation time. Current consumption of different nodes of sensor at energy saving mode is specified in Table I. This table demonstrates that RF transceiver is the largest energy consumer of the sensor. Microprocessor program must be prepared so that the RF transceiver is used as less as possible.

If possible, it is desirable to make the processing of data using the sensor microprocessor and sending to data collection unit only the final result, not all data. This approach should be used for calculation of average value of several ambient light sensor measurements.

Also during inactivity of sensor all nodes should fall into low-power modes.

\section{EleCtrochemicAl DOUBle-LAYER CAPACITOR AS A STORAGE OF ENERGY}

\section{A. General information}

Electrochemical double-layer (ECDL) capacitor or supercapacitor behaves similarly to conventional capacitor, but the manufacturing process and materials are different. These technologies can significantly increase the capacitance [7]. The energy stored in capacitor can be calculated

$$
E_{C}=\left(C V^{2}\right) / 2 \text {, }
$$

where $\mathrm{C}$ is capacitance in farads, $\mathrm{V}$ is charged capacitor voltage.

Equation (6) represents total stored energy of supercapacitor. At the same time it is quite difficult to utilize whole stored energy, because voltage of the capacitor drops with decrease of accumulated energy. Usable energy can be calculated using expression:

$$
E_{C U}=C\left(V^{2}-V_{d s c h}^{2}\right) / 2,
$$

where $V_{\text {dsch }}$ is voltage to which the capacitor is discharged.

Simplified electrical equivalent model of ECDL capacitor is shown in Fig. 5.

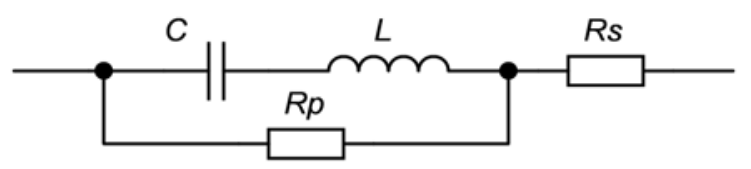

Fig. 5. Simplified ECDL capacitor equvalent electrical model.

In this model combination of series resistance Rs and parallel resistance $\mathrm{Rp}$ represents supercapacitor equivalent series resistance (ESR). Usually several farad capacitor has several tens or hundreds of milliohms ESR. We are going to use ECDL capacitor as a power supply for small load, which does not require high current. It means that series resistance does not affect losses in our case.

Parallel resistance represents leakage current and self discharge process of ECDL. We are going to store energy for a long period so it is an important object of evaluation.

\section{B. Capacitor Charging Process}

As discussed previously the supercapacitor has low ESR. This is a very good property for loads with high currents. At the same time it is a problem for supercapacitor charging process. It is necessary to limit charging current to protect charger from overload.

There are two protection functions of charger: limiting of capacitor charging current and limiting of input current of charger (Fig. 6). Voltage of capacitor increases linearly in the first case. Charging time is fixed and depends only on output current. Experimentally measured curves of the charging process for $10 \mathrm{~F} 2.5 \mathrm{~V}$ rated voltage Maxwell PC10 series supercapacitor with $180 \mathrm{~m} \Omega$ ESR are shown in Fig. 7. a)

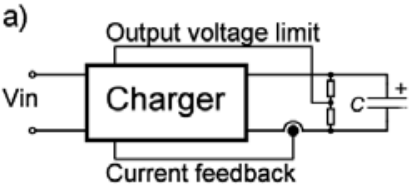

b)

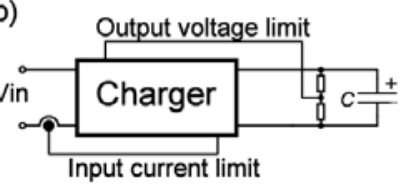

Fig. 6. Charger protection functions: a) output current limit; b) input current limit.

Energy accumulation process is faster in the case of limiting of input current. Experimental measurements were made with LTC3619 IC [8] and the results are shown in Fig. 8 and Fig. 9. 


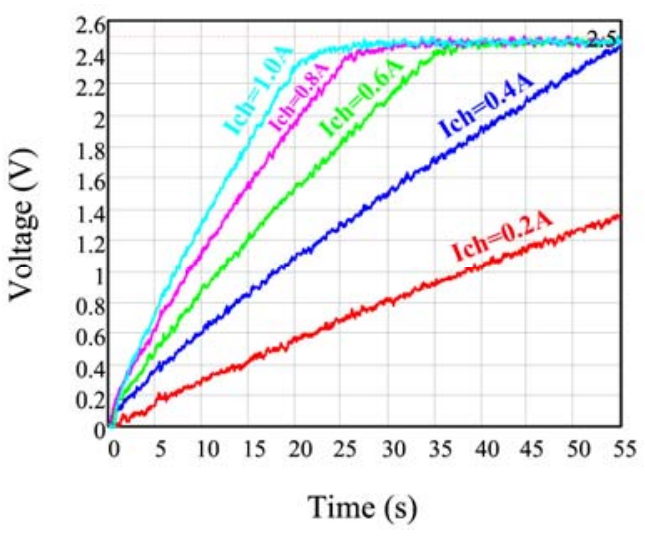

Fig. 7. 10F supercapacitor charging time at constant charging current.

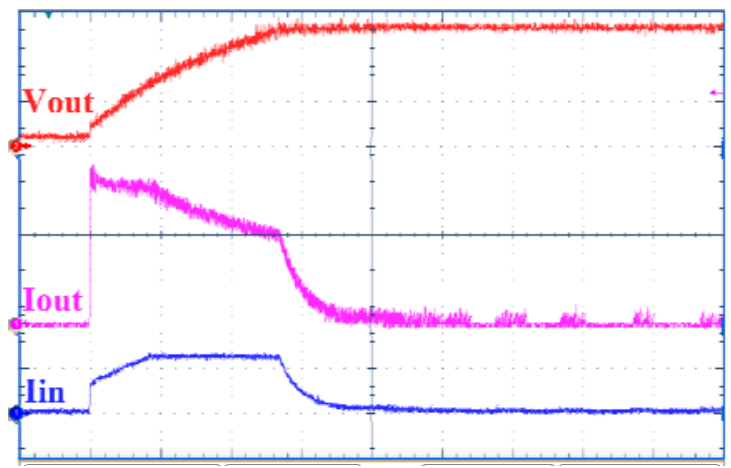

Fig. 8. 10F supercapacitor charging process in the case of limiting of charger input current $\left(\mathrm{V}_{\text {in }}=5 \mathrm{~V} ; 5 \mathrm{~s} /\right.$ div; $500 \mathrm{~mA} /$ div; $1 \mathrm{~V} /$ div $)$.

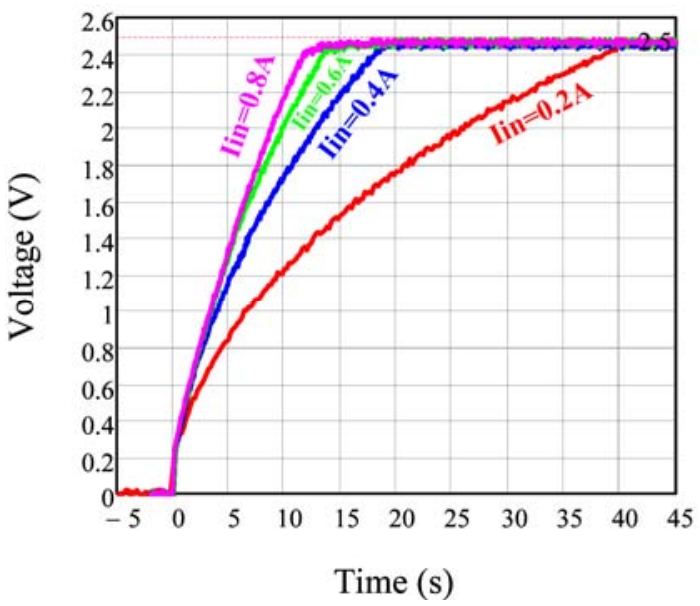

Fig. 9. Supercapacitor charging time at constant charger input current.

Input current limiting method is preferable for capacitor charging, as it allows accelerating energy accumulation process by increasing the input voltage, at the same time the charger is protected from overload.

\section{Process of the Energy Extraction from ECDL}

As it is seen from (7) total usable energy of supercapacitor also depends on the ability of voltage regulator to operate at very low input voltage. The lower is the voltage at which regulator operates, the more usefully the capacitance of ECDL will be used.

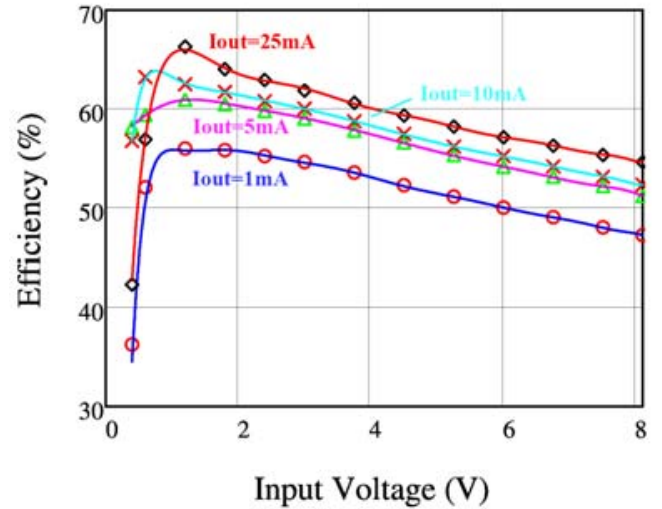

Fig. 10. Efficiency of SEPIC topology voltage regulator at different input voltages and loads

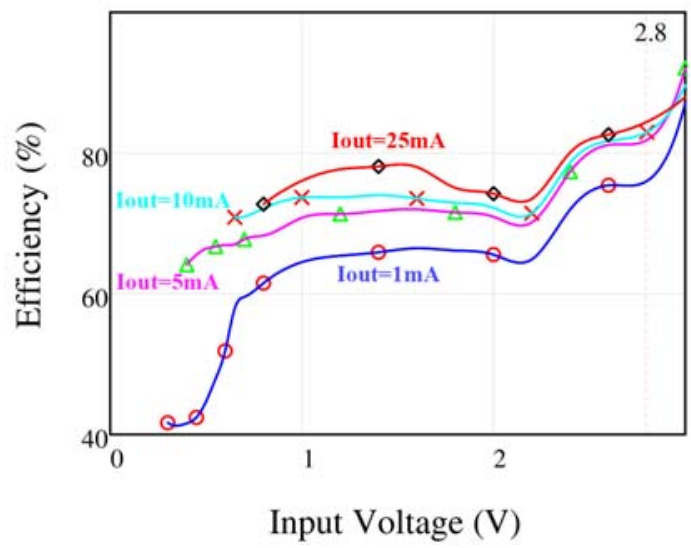

Fig. 11. Efficiency of boost topology voltage regulator at different input voltages and loads

The experiments were made with voltage regulators of boost and single-ended primary inductor converter (SEPIC) topologies based on LM2621 integrated circuit [9]. The components used and the conditions for both cases are identical. The results are summarized in Fig. 10 and Fig. 11.

If necessary, it is possible to increase total stored energy connecting several capacitors in series or parallel. Voltage regulator topology should be buck-boost for series connection. Series connection of supercapacitors requires balancing circuits to ensure that voltage across all cells is distributed uniformly. Otherwise, the voltage of any cell can exceed the rated value. Additional balancing circuits increase total costs of the final device.

\section{Assessment of Self Discharge of ECDL}

According to Fig. 5 supercapacitor self-discharge can be estimated using RC constant:

$$
V_{C}=V_{\text {init }} \cdot e^{-t / R_{p} C}
$$

where $\mathrm{V}_{\text {init }}$ is initial voltage of capacitor. Usually datasheet of supercapacitor specifies maximal leakage current $\mathrm{I}_{\mathrm{lkg}}$ at rated voltage $V_{\text {rated }}$. Then equivalent parallel resistance can be found as $R_{\mathrm{p}}=\mathrm{V}_{\text {rated }} / \mathrm{I}_{\mathrm{lkg}}$. 


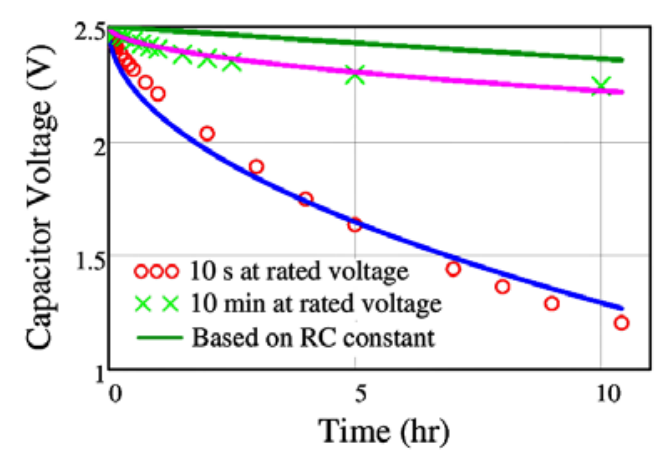

Fig. 12. 10F supercapacitor self-discharge process: analitically calculated (based on RC constant) and experimentally measured after different charging time at rated voltage

Analytically calculated (solid lines) and experimentally measured (points) supercapacitor self-discharge process is shown in Fig. 12.

It can be found that self discharge process depends on charging time after the rated voltage is reached. Datasheet specifies leakage current after $72 \mathrm{hr}$ charging. It is quite difficult to find from datasheet appropriate $R_{p}$ values for different charging time.

Estimated curves based on experimental data diffusion were constructed by equation

$$
V_{C}=V_{\text {init }}-B \cdot \sqrt{t}
$$

where $\mathrm{B}$ is a constant depending on charging time after the rated voltage of supercapacitor is reached.

Table II specifies ECDL parameters after 10 hours, when supercapacitor was charged with rated voltage $(2.5 \mathrm{~V})$.

\section{E. Duration of Operation}

Table III specifies data about sensor power consumption and duration of operation at different conditions. Operation time was calculated and measured for $10 \mathrm{~F}$ supercapacitor with $2.5 \mathrm{~V}$ rated voltage (voltage regulator allows to discharge capacitor till $0.8 \mathrm{~V}$ ). RF transceiver sends data every second. It can be concluded from Table III that operation time of sensor can be increased in different ways. The most efficient way is the optimization of operation algorithm. If data receiving is not provided, RF transceiver should be put in sleep mode, because in receiving mode it consumes about $20 \mathrm{~mA}$. Operation time can also be increased by choosing an appropriate voltage regulator.

TABLE II

Comparison of Self-Discharge Estimation Methods (VAlues - 10 HOURS AFTER CHARGING)

\begin{tabular}{|l|c|c|c|c|}
\hline $\begin{array}{c}\text { Method, } \\
\text { Conditions }\end{array}$ & Constant & $\begin{array}{c}\text { Voltage } \\
\text { (V) }\end{array}$ & $\begin{array}{c}\text { Stored } \\
\text { Energy (J) }\end{array}$ & $\begin{array}{c}\text { Usable } \\
\text { Energy* (J) }\end{array}$ \\
\hline $\begin{array}{l}\text { RC constant } \\
\text { (after 72 hr) }\end{array}$ & $\begin{array}{c}\mathrm{Rp} \\
6.25 \mathrm{E}+4\end{array}$ & 2.36 & 27.8 & 24.6 \\
\hline $\begin{array}{l}\text { Diffusion } \\
\text { (after 10 sec) }\end{array}$ & $\begin{array}{c}\mathrm{B} \\
4.9 \mathrm{E}-2\end{array}$ & 1.29 & 8.3 & 4.7 \\
\hline $\begin{array}{l}\text { Diffusion } \\
\text { (after 10 } \mathrm{min})\end{array}$ & $\begin{array}{c}\mathrm{B} \\
1.1 \mathrm{E}-2\end{array}$ & 2.22 & 24.6 & 21.4 \\
\hline
\end{tabular}

TABLE III

COMPARISON OF DURATION OF OPERATION AT DIFFERENT CONDITIONS

\begin{tabular}{|c|c|c|c|c|}
\hline \multicolumn{3}{|c|}{ Conditions } & Calculated & Measured \\
\hline \multirow{4}{*}{$\begin{array}{l}\text { Power } \\
\text { consumption } \\
\text { at } 1.5 \mathrm{~V} \text { input } \\
\text { voltage }(\mathrm{mW})\end{array}$} & \multirow{2}{*}{$\begin{array}{c}\text { Not } \\
\text { optimized }\end{array}$} & Boost & 93.3 & 86.4 \\
\hline & & SEPIC & 107.7 & 102.8 \\
\hline & \multirow{2}{*}{ Optimized } & Boost & 4.9 & 5.8 \\
\hline & & SEPIC & 5.6 & 6.7 \\
\hline \multirow{4}{*}{$\begin{array}{l}\text { Duration of } \\
\text { operation }\end{array}$} & \multirow{2}{*}{$\begin{array}{c}\text { Not } \\
\text { optimized }\end{array}$} & Boost & $5 \mathrm{~min}, 2 \mathrm{~s}$ & $5 \mathrm{~min}, 18 \mathrm{~s}$ \\
\hline & & SEPIC & $4 \mathrm{~min}, 17 \mathrm{~s}$ & $4 \mathrm{~min}, 46 \mathrm{~s}$ \\
\hline & \multirow{2}{*}{ Optimized } & Boost & $1 \mathrm{~h}, 10 \mathrm{~min}$ & $1 \mathrm{~h}, 15 \mathrm{~min}$ \\
\hline & & SEPIC & $1 \mathrm{~h}, 2 \mathrm{~min}$ & $1 \mathrm{~h}, 3 \mathrm{~min}$ \\
\hline
\end{tabular}

\section{V.COMPARISON WITH LI-ION BATTERY AND EVALUATION OF COSTS}

The capability of Li - ion batteries are four orders of magnitude greater than electrostatic capacitors and two - fold greater than supercapacitors [10], [11] but supercaps have extended life cycle in comparison with rechargeable batteries.

To evaluate costs of energy storage system it is necessary to take into account price of energy storage itself, price of charging equipment and total possible stored energy per volume unit, which depends on life cycle:

$$
\operatorname{Costs}_{\text {rel }}=\frac{\text { Costs }_{\text {total }} \times \mathrm{Vol}}{E_{\text {sin gle }} \times n},
$$

where Costs $_{\text {rel }}$ is relative costs of the life cycle of energy storage system $\left(€ \cdot \mathrm{cm}^{3} / \mathrm{W} \cdot \mathrm{h}\right)$, Costs total are costs of energy storage and charging equipment $(€), \mathrm{E}_{\text {single }}$ is usable stored energy at one charge/discharge cycle $(\mathrm{W} \cdot \mathrm{h}), \mathrm{n}$ is life cycle (number of charge/discharge cycles till capacity drops down per $20 \%$ of nominal value).

Comparison of the life cycle costs of different type energy storages available at the market is given in Table IV. Total costs in this table also include price of charging equipment (charger ICs) and price of accessories (battery holders).

According to this table life cycle costs of supercap are approximately 5 times less than the costs of Li-ion rechargeable battery and approximately 30 times less than the costs of lithium non-rechargeable battery in long period term.

TABLE IV

ASSESSMENT OF THE LIFE CYCLE COSTS OF DIFFERENT TYPE

\begin{tabular}{|c|c|c|c|c|c|}
\hline Type & $\begin{array}{c}\text { Total } \\
\text { costs, } \\
(€)\end{array}$ & $\begin{array}{c}\text { Volume, } \\
\left(\mathrm{cm}^{3}\right)\end{array}$ & $\begin{array}{c}\text { Usable } \\
\text { stored } \\
\text { energy, } \\
(W \cdot h)\end{array}$ & $\begin{array}{c}\text { Life } \\
\text { cycle, } \\
\text { (cycles) }\end{array}$ & $\begin{array}{c}\text { Life cycle } \\
\text { costs } \\
\left(€ \cdot \mathrm{cm}^{3} / \mathrm{W} \cdot \mathbf{h}\right)\end{array}$ \\
\hline $\begin{array}{l}\text { Supercap } \\
\text { (Maxwell } \\
\text { PC10) }\end{array}$ & 8.40 & 3.35 & $7.8 \cdot 10^{-3}$ & 500000 & $7.2 \cdot 10^{-3}$ \\
\hline $\begin{array}{l}\text { Li-ion } \\
\text { (Multicomp } \\
\text { LIR2450) }\end{array}$ & 3.32 & 2.36 & 0.43 & 500 & $36.3 \cdot 10^{-3}$ \\
\hline $\begin{array}{l}\text { Lithium } \\
\text { (Panasonic } \\
\text { CR-2032) }\end{array}$ & 0.15 & 0.97 & 0.68 & 1 & $214 \cdot 10^{-3}$ \\
\hline
\end{tabular}
ENERGY STORAGES 


\section{CONCLUSIONS}

The supercapacitor as primary energy storage of autonomous power supply for light sensor of illumination measurement test bench was discussed in this paper. The charging process and the energy extraction process of supercapacitors were described in the article.

The evaluation of the results has shown that the main criterion for improving energy efficiency and increasing the operating time of the wireless node powered from supercapacitor is the optimal algorithm of the device (microprocessor program), which involves minimal use of the $\mathrm{RF}$ transceiver. It is also necessary to maximize usage of power-saving modes of individual nodes.

With the use of supercapacitor the charging time of energy storage of the prototype of light sensor for the test bench has been reduced to 15-20 seconds (approximately 6 times faster in comparison with Li-ion for the same stored energy amount). The optimized algorithm allows extending operation time by 14 times (Table III). Selected supercapacitor Maxwell PC10 can provide energy for more than one hour operation (sufficient operation time for one test).

Assessment of life cycle costs showed that the use of the ultracapacitors as energy storage for wireless device can be economically profitable in long time period (at least 100000 charge-discharge cycles). The limitations of such systems are volume of capacitors, self discharge process and limitations on the use under high temperature conditions. These parameters should be evaluated for each system individually.

\section{ACKNOWLEDGMENT}

This work has been supported by the National Research Program "LATENERGI".

\section{REFERENCES}

[1] O. Tetervenoks, A. Avotins, Implementation of Wireless Communication for LED Luminary Light Efficiency Evaluation Stand, Student Forum Proceedings of the 7th International ConferenceWorkshop Compatibility and Power electronics CPE 2011, Tallinn, Estonia, June 3, 2011, pp. 72-76.

[2] Lahiri, K.; Raghunathan, A.; Dey, S.; Panigrahi, D.; , "Battery-driven system design: a new frontier in low power design ," Design Automation Conference, 2002. Proceedings of ASP-DAC 2002. 7th Asia and South Pacific and the 15th International Conference on VLSI Design. Proceedings. , vol., no., pp.261-267, 2002

[3] Chulsung Park; Lahiri, K.; Raghunathan, A.; , "Battery discharge characteristics of wireless sensor nodes: an experimental analysis," Sensor and Ad Hoc Communications and Networks, 2005. IEEE SECON 2005. 2005 Second Annual IEEE Communications Society Conference on , vol., no., pp. 430- 440, 26-29 Sept., 2005

[4] Hang Su; Xi Zhang; , "Battery-dynamics driven tdma mac protocols for wireless body-area monitoring networks in healthcare applications," Selected Areas in Communications, IEEE Journal on, vol.27, no.4, pp.424-434, May 2009

[5] Merrett, G.V.; Weddell, A.S.; Lewis, A.P.; Harris, N.R.; Al-Hashimi, B.M.; White, N.M.; , "An Empirical Energy Model for Supercapacitor Powered Wireless Sensor Nodes," Computer Communications and Networks, 2008. ICCCN '08. Proceedings of 17th International Conference on, vol., no., pp.1-6, 3-7 Aug. 2008

[6] Philips Semiconductors, $I^{2} C$-bus specification and user manual, user manual, 2012, available electronically at http://www.npx.com [Accessed March 11, 2012]

[7] R. Kötz, M. Carlen, "Principles and applications of electrochemical capacitors," Electrochim. Acta 45 (2000) 2483-2498.
[8] Linear Technology, LTC3619 400mA/800mA synchronous step-down DC/DC with average input current control, datasheet, 2009, available electronically at http://cds.linear.com/docs/Datasheet/3619f.pdf [Accessed March 13, 2012]

[9] National Semiconductor, LM2621 low input voltage, step-up DC/DC converter, datasheet, 2005, available electronically at http://www.national.com [Accessed March 15, 2012]

[10] M. Belleville, E. Cantatore, H. Fanet, P. Fiorini, P. Nicole, M.J.M. Pelgrom, C. Piguet, R. Hahn, C. Van Hoof, R. Vullers, M. Tartagni, Energy autonomous systems: future trends in devices, technology, and systems, Report, CATRENE Working Group on Energy Autonomous Systems, 2008, Fig. 6, p. 8 .

[11] M. Belleville, H. Fanet, P. Fiorini, P. Nicole, M.J.M. Pelgrom, C. Piguet, R. Hahn, C. Van Hoof, R. Vullers, M. Tartagni, E. Cantatore, "Energy autonomous sensor systems: Towards a ubiquitous sensor technology," Microelectronics Journal, Volume 41, Issue 11, November 2010, Pages $740-745$

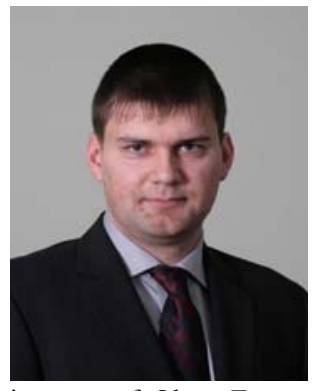

Olegs Tetervenoks received his Bachelor's Degree with Engineer qualification (2010) and Master's (2011) Degree in the field of electrical engineering at Riga Technical University, Faculty of Power and Electrical Engineering. Since 2011 he has been studying for his $\mathrm{PhD}$ at Riga Technical University. The Bachelor thesis was focused on solid state lighting technology development, in particular, on efficient LED power supply development. The Master thesis was devoted to LED light source efficiency evaluation equipment. The area of scientific interests of Olegs Tetervenoks covers microprocessor control systems and LED lighting technologies.

The working experience of Olegs Tetervenoks includes 2 years of research job at Riga Technical University.

Olegs Tetervenoks is IEEE member since 2011

e-mail: olegs.tetervenoks@rtu.lv

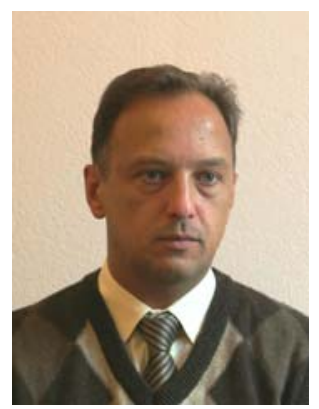

Ilya Galkin received his Bachelor's (1994), Master's (1996) and Doctor's (2001) Degrees in the field of electrical engineering at Riga Technical University, Faculty of Power and Electrical Engineering, Department of Power Electronics and Electrical Technologies. The main research field includes design and applications of matrix converters. In particular it regards integrated designs with the matrix converters, smart control of their semiconductor switches, thermal and conductor's design. Another research field includes smart power supplies for various applications, for example, for LED lighting. The working experience of Ilya Galkin includes 6 year of practical engineering job at research and manufacturing enterprise "Lasma" (Latvia) in the field of elaboration and development industrial automatics, as well as 14 years of research and educational job at Riga Technical University. At the given time he is a professor at the Department of Power Electronics and Electrical Technologies of RTU-EEF-IEEI. Ilya Galkin is the author of various publications.

Ilya Galkin is IEEE member since 2006 in societies of Power Electronics, Industrial Electronics, Automatic control and Education. e-mail: gia@eef.rtu.lv

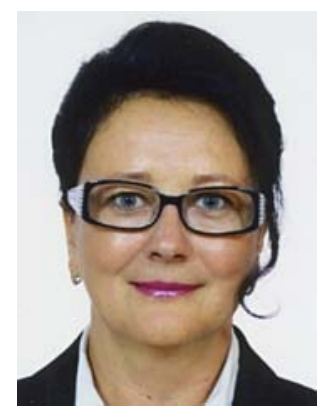

Jelena Armas received her engineering education and Ph.D. degree in Electrical Drives and Power Electronics in Tallinn University of Technology 1982 and 2008 respectively. In 1982-1985, she worked in Tallinn University of Technology. Since 2006 she has been working in Elektrilevi OÜ. Her research interests include analysis of the quality of street lighting and implementation of new measurement methods. She has authored more than 15 publications on street lighting.

e-mail: jarmas@hot.ee 